withstanding it is the best Act of any State and is as ably enforced as any of the various State Medical Acts. The present board have held seven quarterly meetings, at which eighty-six physicians have applied to be examined. Of this number six were refused admission to the class, not having taken three full courses of medical lectures of six months duration each. Of the eighty entering the various examinations fifty-one were licensed. Some of this number underwent several quarterly examinations before being successful. Twenty-nine were rejected, not possessing the knowledge of Medicine required by the board. Of those who passed, forty-nine are Regulars and two Homoeopaths. Of those failing to pass the examination, eighteen were Regulars, eight were Homcopathic, and only three were eclectic physicians. Those passing the examinations of the board were mostly graduates of McGill, Harvard, Chicago Medical, and the University of Michigan, Students who were graduates of the two-term schools and those having sessions of less than six months duration, are of course prohibited the privilege of practice in the State.

PERRY H. MiliLARD, M.D.

St. Paul, Minn.

\section{A Needle in the Heart.}

To the Editor:-Noticing the article in the last JournaL, by Sara A. Kime, M.D., "The Migration of a Needle," calls to my mind a case that came under my own observation about twentyeight years ago, in the village of Warsaw, Western New York, where I was then practicing.

I was called to attend Mr. T., æt, 20 years, who for many weeks had been suffering severe pain in the region of the heart, attended with violent palpitation upon making any considerable exertion. Not a moment passed, unless he was asleep, that he was not tormented with an indescribably oppressed feeling about the chest. The pulse was somewhat accelerated and irregular. I had the clothing removed from the chest, so that I could make a thorough examination by inspection, as well as by auscultation and percussion, and while passing my hand over the heart to ascertain the force of its impulse, I felt a little hardened elevation. It was not visible when looking at the chest, but it could be readily felt with the finger, or the flat surface of the hand pressed gently upon it, and moved upwards and downwards.

With a bistoury I incised the skin directly over it, and with a pair of forceps removed an ordinary sewing needle an inch and a-half in length, All the unpleasant symptoms very soon subsided, and in a week or two my patient was quite as well as he had ever been.

From the location of the needle, and the attend- ing symptoms, I was quite sure it had, for a time, found a resting place in the very substance of the heart itself. 734 College Ave, Racine, Wis.

JOHN G. MEACHEM, M.D.

\section{BOOK NOTICES.}

A Clinical Atlas of Venereal and Skin Diseases, Including Diagnosis, Prognosis and TreatMen't, By Rober' W. TAylor, A.M., M.D., Surgeon to Charity Hospital, New York, etc., etc. Philadelphia: Lea Brothers \& $\mathrm{Co}$. I888. In eight parts. Price per part $\$ 2.50$.

We have received the first four parts of this handsome work, which is published in a manner highly creditable to the well-known house of Lea Brothers \& Co. The lithographs are executed by the Sinclairs, and it is needless to say are in the highest style of the art. The paper is superb, and the typography is exquisite.

There is no formal preface and the author commences part I by plunging directly into his subject. The publishers, however, have supplied a detached "prefaratory note" in which they say:

"As no clinic, however large, can furnish the necessary materials, the entire literature of the subjects has been searched for its best illustrations, and selections made with proper permission of living authors. These have been completed by numerous reproductions from a collection of original paintings from life, gathered by the Author during many years of practice."

The well-known views of Dr. Taylor on venereal diseases are set forth on these stately pages in a pleasant and straightforward manner; but there is one blemish in the first parts that we would gladly pass over, except that our duty to our readers requires that book notices in these columns shall be impartial and accurate. This blemish is the frequent occurrence of such phrases as this, on page I67: "For further particulars as to the use of preparations of iodine, see Bumstead and Taylor, page 875 " - -and again on the same page, "For full particulars of the method of using inunctions see Bumstead and Taylor on veneral diseases, page 86r." These remarks seem to imply that the Atlas is intended as a companion to the work of Bumstead and Taylor, whereas, in fact it is intended to be, and really is, complete in itself.

The author of the atlas surely could not have intended to depreciate this later work, and we only regret that such a magnificent work should not contain all the author thinks the text requires to fully declare his meaning.

Dr. Taylor is extremely cautious in his prognoses, and his candor is commendable ; thus in speaking of the etiology of acne simplex, he says : "The pivotal questions are, what causes the inflammation that precedes the formation of the plug? 